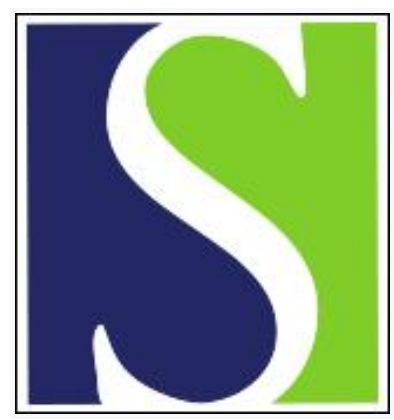

Scand J Work Environ Health 2009;35(4):309-318

https://doi.org/10.5271/sjweh.1332

Published online: 27 May 2009, Issue date: 31 Jul 2009

Medical program for shift workers - impacts on chronic disease and mortality outcomes

by Oberlinner C, Ott MG, Nasterlack M, Yong M, Messerer P, Zober A, Lang S

Affiliation: Occupational Medicine \& Health Protection Department, BASF SE, 67056 Ludwigshafen, Germany. christoph.oberlinner@basf.com

Refers to the following texts of the Journal: 2008;34(3):206-212 1999;25(2):100-104 2005;31(3):179-183 2005;31(1):30-35 2007;33(1):45-50 2002;28(1):64-71

The following articles refer to this text: 2010;36(2):85-95; 2014;40(5):502-510; 2018;44(3):229-238

Key terms: chronic disease; evaluation; health promotion; medical program; mortality; shift work; shift worker; work schedule tolerance; workplace

This article in PubMed: www.ncbi.nlm.nih.gov/pubmed/19471844 


\title{
Medical program for shift workers - impacts on chronic disease and mortality outcomes
}

\author{
by Christoph Oberlinner, MD, ${ }^{1}$ M Gerald Ott, PhD, ${ }^{1}$ Michael Nasterlack, MD, ${ }^{1}$ Mei Yong, PhD, MSc, MPH, ${ }^{1}$ \\ Peter Messerer, MSc, ${ }^{1}$ Andreas Zober, MD, PhD, ${ }^{1}$ Stefan Lang, MD ${ }^{1}$
}

Oberlinner C, Ott MG, Nasterlack M, Yong M, Messerer P, Zober A, Lang S. Medical program for shift workers impacts on chronic disease and mortality outcomes. Scand J Work Environ Health. 2009;35(4):309-318.

\begin{abstract}
Objective In 1983, global chemical company BASF SE implemented a supplemental health protection program to help its employees cope with the stressors associated with shift work. The program included comprehensive medical examinations and health promotion activities targeted at shift workers. The aim of this study was to to assess the possible long-term health impacts of the program.

Methods Cohorts of 14128 male rotating shift and 17218 male day wage employees were established via electronic job history searches. Health examination and mortality records were linked to job histories and studied over an 11-year period.

Results Between 1996 and 2006, there were 414 and 463 deaths among rotating shift and day work employees, respectively. Mortality risks were marginally lower among shift working employees when taking age and job level into consideration, and remained so when cigarette smoking, alcohol intake, and existing chronic disease conditions were included as explanatory factors. The incidence of obesity, diabetes, and diseases of the circulatory and digestive system, as diagnosed or reported during health examinations, was higher among shift work employees, possibly as a consequence of enhanced medical surveillance or a direct effect of shift work.
\end{abstract}

Conclusion Incorporation of extensive occupational medical examinations, health seminars, and other intervention programs may help mitigate the long-term health consequences of shift work.

Key terms shift work; evaluation; health promotion; workplace; work schedule tolerance.

Beyond the direct effects of shift work on disturbance of sleep, fatigue, gastrointestinal disorders, and its exacerbation of existing health conditions, questions have been raised about the long-term health consequences of shift work (1). In men, concerns relate primarily to endocrine, nutritional, and metabolic disorders, including obesity and diabetes, circulatory disease, and digestive system illnesses (1-10). Observational studies on the health of shift workers have often yielded inconsistent results (11-12), which may be partly due to difficulties in addressing socioeconomic and other differences between day and shift work employees (13).

Shift work is a necessary requirement in largescale chemical manufacturing due to the nature of production processes. Consequently, global chemical corporation BASF Societas Europaea employs large numbers of individuals in shift work at its manufacturing facilities in Ludwigshafen, Germany. In 1983, representing employees and the works management of BASF, the Works Council entered into an agreement providing additional benefits for shift work employees in the form of (i) routine medical examinations including an assessment of suitability for shift work, (ii) health promotion retreats lasting up to three weeks, and (iii) financial compensation for employees leaving shift work for health reasons. BASF's Occupational Medical and Health Protection Department administers the medical examination and other related health promotion programs and also provides 24-hour, on-site emergency medical services for employees (14-17). The Medical Department maintains a medical information system to support the various occupational health activities of the Department. That system, in turn, facilitates the evaluation of the effectiveness of the various departmental programs.

\footnotetext{
1 Occupational Medical and Health Protection Department, BASF Societas Europaea, Ludwigshafen, Germany.
}

Correspondence to: Dr C Oberlinner, Occupational Medicine \& Health Protection Department, BASF SE, 67056 Ludwigshafen, Germany. [E-mail: christoph.oberlinner@basf.com] 
To assess the effectiveness of these shift work programs, the Medical Department identified cohorts of wage employees assigned to rotating shift or day work and followed them over an 11-year period. Targeted outcomes included the acute injury and illness experience at work and the chronic disease and mortality experience of both cohorts. In this report, we evaluate the chronic disease experience and the risk of premature death between 1996 and 2006. Our findings are discussed in the context of the various occupational health protection programs offered through the Medical Department.

\section{Study population and methods}

\section{Study population}

The Ludwigshafen site includes BASF production, research, and administrative offices. Approximately one fourth of all site employees perform rotating shift work. Other forms of shift work (eg, schedules related to providing emergency services and security) are utilized on a limited scale, but are not addressed in the present evaluation. As described in more detail elsewhere (18), the study population consisted of 14128 wage employees, who completed at least one year of full-time, rotating shift work, beginning at some time between 1995 and 2005. The assessment was limited to men as few women were assigned to shift work. The referent population consisted of 17218 male wage employees, who completed one or more years of day work during the same time period and who did not qualify for the shift work cohort.

For each employee in the study, we extracted the start and end dates of all relevant jobs held between 1995 and 2006 from electronic work history files. Additional items captured for each job were: type of shift, level of job (manual labor or skilled/supervisory), and type of work (production, maintenance, or other). Complete information on type of shift was not available before 1995 .

\section{Shift schedules}

Throughout the study period, the shift schedules used at the Ludwigshafen site were fast-forward rotating 12hour shifts with the day shift beginning at 06.00 hours and the night shift at 18.00 hours. Total working time per year was set at 1950 hours; overtime hours were equalized by additional time off. Observational studies have suggested that such schedules are beneficial to health and work-life balance compared to slow-forward rotating or backward rotating schedules (19).

\section{Medical program overview}

The ultimate goal of BASF's various health management programs is to maintain shift workers' personal health, workability, and fitness for duty. The programs comprise multiple measures that combine medical examinations, health promotion initiatives, and 24-hour emergency medical services. A detailed description of the aims and scopes of these programs has been provided in a previous publication (18). The essentials are summarized in the following paragraphs.

In Germany, legislative mandates require employers to provide specific occupational health services to employees and fund insurance programs to cover occupational injuries and illnesses (20). These regulations specify the nature of medical examinations to be conducted relative to specific health hazards and set minimum requirements for the provision of medical services. With the consent of the Works Council, the Medical Department may undertake additional disease prevention initiatives $(15-17,21)$.

As per the 1983 agreement, a medical examination program specific to shift work was initiated. A preentry to shift work examination includes spirometry, resting electrocardiogram, laboratory tests, and a complete physical examination. Based on the findings, physicians may make recommendations for undertaking shift work, on which the employee is then free to act. Historically, employees had been precluded from entering shift work in the presence of certain conditions such as epilepsy, asthma requiring medication, recent myocardial infarction, severe hypertension, pronounced functional heart disease, and malignancies currently under treatment. Periodic medical examinations are also provided once every three years and annually for employees over the age of 50 .

Both rotating shift and day work employees may participate in health seminars and retreats. The retreats require medical clearance and consist of seminars on various health topics, as well as physical activities like Nordic walking, gymnastics, and swimming. Slots are apportioned based on workload factors such as vigilance and physical exertion requirements of the job. By design, a large number of slots are apportioned to shift work employees. The program administrator documents and maintains the dates of participation and the type of seminar. For the purposes of our study, data were extracted from 1986-2005.

\section{Targeted health outcomes}

We obtained information on the incidence and prevalence of chronic health conditions as part of scheduled and consultative medical examinations that were performed by experienced specialist physicians working 
in the BASF out-patient clinic. Diagnoses were based on hospital records or internal diagnostic findings in addition to anamnesis; science-based guidelines were used for diagnostics and therapy. Each condition was coded according to the Tenth Revision of the International Classification of Diseases (ICD-10). Details concerning how diagnoses were qualified and entered into the Medical Record System are provided elsewhere (18).

For active employees, vital status follow-up was available through 2006 via personnel records; pension records were used after the termination of active employment. Employees, who left the company without a pension benefit, were considered to be "lost-to-followup" as of their last date of active employment. However, as a pension benefit is accrued after five years of employment, the "lost-to-follow-up" percentages for the cohorts were quite low $(<0.5 \%)$. Information on cause of death is incomplete due to data restrictions and, hence, was not utilized in this assessment.

\section{Data analysis}

We used SAS Version 8 or Version 9.1 software (SAS Institute, Cary, NC, USA) to carry out descriptive and statistical analyses. We examined disease prevalence on entry to the study to assess potential selection effects of certain chronic disease conditions on vital status outcome. We also assessed incidence rates for these disease conditions in employees with no known prior diagnosis in the respective disease categories. The risk period was defined as the time between the entry date and the date of the most recent follow-up examination; thus, results pertain only to employees during their period of active company employment. We carried out analyses via a Cox proportional-hazards model approach using PROC PHREG in SAS. The following risk factors were examined: (i) shift versus day work, (ii) age on entry to follow-up, (iii) job level, (iv) cigarette smoking history, and (v) alcohol intake. To address the potential information bias resulting from the more frequent medical examinations offered to shift work employees, we used a stratified regression approach to account for the differences in examination frequency with strata being formed based on the mean interval between examinations. To accommodate potential differences in the knowledge of existing chronic disease conditions, we included as an independent explanatory variable the interval between the last examination date before the beginning of the risk period and the date of entry to the follow-up.

We assessed mortality using both modified life table and Cox proportional-hazard model approaches. Person years were accumulated between the date of entry to the study and the "last known alive" date up to the end of 2006. Due to the inclusion criterion of having achieved at least one year of shift or day work beginning in 1995, the entry date could be no earlier than 1996. For employees who began the study period in day work jobs and later changed to rotating shift work, the qualifying person years during day work were included in the calculation of day work. However, the impact was minimal. We calculated confidence intervals for standardized mortality ratios on Poisson distribution assumptions. For external mortality comparisons, we used five-year age- and calendar-specific death rates for the total German male population (1995-2006) (22). For internal comparisons, the potential differential impact of shift work on mortality was assessed relative to: (i) age on entry to follow-up, (ii) job level, (iii) cigarette smoking history, (iv) alcohol intake, and (v) prevalent chronic disease conditions known on entry to follow-up.

\section{Results}

Baseline characteristics of rotating shift and day work employees are presented in table 1 on the following page. The mean age on entry to the study was very similar between the cohorts -38.0 and 38.1 years of age for shift and day work employees, respectively. Rotating shift employees were more likely to be assigned to jobs involving manual labor than day workers and were also more likely to be assigned to production than maintenance or production support jobs. These latter activities are generally undertaken during daytime work hours. Cigarette smoking was more prevalent among shift than day work employees; whereas, there was no notable difference in alcohol intake patterns between the two cohorts. Participation in health seminar retreats was higher among shift than day work employees, particularly during the period after entry to the study.

Vital status follow-up and medical examination history are summarized in table 2 . The duration of follow-up was longer on average among shift compared to day work employees; the "lost-to-follow-up" percentages were low in both cohorts. Due to the extensive examination program, nearly $95 \%$ of shift work employees had at least one occupational medical examination between 1991 and entry to the study whereas only $70 \%$ of day work employees had one or more examinations prior to the entry date. Shift work employees participated in twice as many examinations per work year as day work employees during the follow-up period.

Prevalence rates for selected disease categories on entry to the study were determined for individuals 
Table 1. Selected baseline characteristics of rotating shift and day work cohorts.

\begin{tabular}{|c|c|c|c|c|c|c|c|c|}
\hline & \multicolumn{4}{|c|}{ Rotating shift (N=14 128) } & \multicolumn{4}{|c|}{ Day work (N=17 218) } \\
\hline & $\mathrm{N}$ & $\%$ & Mean & SD & N & $\%$ & Mean & SD \\
\hline Age at entry (years) & .. &.$\cdot$ & 38.0 & 10.6 &.$\cdot$ & .. & 38.1 & 10.8 \\
\hline Start year & .. &.. & 1996.9 & 1.8 &.. & .. & 1997.3 & 2.0 \\
\hline \multicolumn{9}{|l|}{ Job level at entry (wage), 1995- } \\
\hline Manual work & 12146 & 86.0 & .. & .. & 8222 & 47.8 &.. & .. \\
\hline Skilled/supervisory work & 1982 & 14.0 & .. & .. & 8996 & 52.2 &.$\cdot$ & .. \\
\hline \multicolumn{9}{|l|}{ Type of work } \\
\hline Production & 12168 & 86.1 & .. & .. & 1740 & 10.1 &.. & .. \\
\hline Maintenance & 684 & 4.8 & .. & .. & 6609 & 38.4 & .. & .. \\
\hline Other & 1276 & 9.0 & .. & .. & 8869 & 51.5 &.$\cdot$ & .. \\
\hline \multicolumn{9}{|l|}{ Cigarette smoking } \\
\hline Current smoker & 6018 & 42.8 & .. & .. & 4660 & 30.7 & .. & .. \\
\hline Former smoker & 5047 & 35.9 & .. & .. & 4703 & 30.9 & .. & .. \\
\hline Never smoker & 2991 & 21.3 & .. & .. & 5842 & 38.4 &.. & .. \\
\hline Not available & 72 & • & .. & .. & 2013 & • &.. & .. \\
\hline \multicolumn{9}{|l|}{ Alcohol intake (average drinks per week) } \\
\hline 0 & 4575 & 32.7 & .. & .. & 3983 & 28.4 &.. & .. \\
\hline $1-2$ & 4840 & 34.6 & .. & .. & 5173 & 36.8 & .. & .. \\
\hline $3-6$ & 3250 & 23.2 & .. & .. & 3186 & 22.7 & .. & .. \\
\hline $7-13$ & 1115 & 8.0 & .. & .. & 1381 & 9.8 & .. & .. \\
\hline$\geq 14$ & 220 & 1.6 & .. & .. & 317 & 2.3 & .. & .. \\
\hline Not available & 128 & $\cdot$ & .. & .. & 3178 & · &.. & .. \\
\hline \multicolumn{9}{|l|}{ Health seminar days, 1986-2005 } \\
\hline Total health seminar days & 172229 & .. & .. & .. & 143695 & .. & .. & .. \\
\hline Seminar days per work year prior to entry & 0.76 & .. & .. & .. & 0.61 & .. & .. & .. \\
\hline Seminar days per work year after entry & 0.68 & .. & .. & .. & 0.31 & .. & .. & .. \\
\hline
\end{tabular}

Table 2. Vital status follow-up and medical examination history by shift status.

\begin{tabular}{|c|c|c|c|c|c|c|c|c|}
\hline & \multicolumn{4}{|c|}{ Rotating shift ( $N=14$ 128) } & \multicolumn{4}{|c|}{ Day work (N=17 218) } \\
\hline & N & $\%$ & Mean & SD & N & $\%$ & Mean & SD \\
\hline \multicolumn{9}{|l|}{ Vital status } \\
\hline Known alive & 13702 & 97.0 & .. & .. & 16703 & 97.0 & .. & .. \\
\hline Deceased & 414 & 2.9 & .. & .. & 463 & 2.7 & .. & .. \\
\hline Lost-to-follow-up & 12 & 0.1 &.. & .. & 52 & 0.3 & .. & .. \\
\hline Years of follow-up & .. & .. & 9.94 & 2.00 &.. &.. & 9.54 & 2.20 \\
\hline \multicolumn{9}{|l|}{ Medical examinations } \\
\hline$\geq 1$ examinations prior to entry & 13393 & 94.8 & .. & .. & 12028 & 69.9 & .. & .. \\
\hline$\geq 1$ examinations after entry & 13410 & 94.9 & .. & .. & 12957 & 75.3 & .. & .. \\
\hline$\geq 1$ examinations prior to and after entry & 12742 & 90.2 & .. & .. & 9382 & 54.5 & .. & .. \\
\hline Total examinations after entry & 118811 & .. & .. & .. & 69318 & .. & .. & .. \\
\hline Total examinations per work year after entry & 0.98 & .. & .. & .. & 0.50 & .. & .. & .. \\
\hline
\end{tabular}

with one or more prior occupational health examinations (table 3). For several categories, the disease prevalence was higher among shift work employees, most notably, for obesity and chronic obstructive pulmonary disease (COPD). For cancer, epilepsy, and ischemic heart disease, prevalence rates were significantly lower among shift work employees.

The incidence of new diagnoses within the corresponding disease categories is summarized in table 4 . Individuals with prevalent cases of category- specific diseases on entry to the study were excluded from the respective analyses. Disease-specific risk ratios for shift relative to day work employees, as provided in the table, were estimated in multivariate models as previously described. Elevated risk ratios were observed for obesity; diabetes; hypertensive diseases; conductive heart disorders; COPD; diseases of the esophagus, stomach, and duodenum; and diseases of the gallbladder, biliary tract, and pancreas. 
Mortality comparisons between shift and day work employees are summarized in table 5 by age group, job level, and interval since entry to the study. The corresponding standardized mortality ratios were consistently lower for shift than day work employees assigned to manual work, but were higher for shift work compared to day work employees among men assigned to skilled or supervisory jobs at entry. Internal mortality comparisons between shift and day work employees (table 6) yielded similar results to the comparisons of standardized mortality ratios in that relative risks were lower for shift compared to day work employees, but not significantly lower. The simplest model (model 1), that included only age on entry to the study and manual versus skilled/supervisory work, yielded a relative risk of 0.95 for shift work and a significantly elevated relative risk for performing manual work of 1.35. Inclusion of cigarette smoking as a co-factor (model 2) marginally decreased the relative risk ratios for both shift work and manual labor. These decreases reflect the higher rate of cigarette smoking in these subgroups of employees.

In model 3, alcohol intake was added as an additional co-factor. In this model, alcohol intake was a significant independent predictor of mortality; however, the relative risk associated with shift work was essentially unchanged. In model 4 , we examined the impact of prevalent conditions at entry for each of the disease categories listed in table 3. Categories were included only if they were determined to be significant explanatory factors in assessing the relative risk of death. A forward-stepwise model was constructed forcing in shift work status at the first step and including all other significant co-factors. In table 6, the final model is shown. The highest relative risk of death was found for a prior diagnosis of cancer. Significant independent contributions were found for eight other disease categories and age on entry to the study; cigarette smoking and alcohol intake remained independent explanatory factors. Although the relative risk for shift work status increased somewhat, it remained below 1.0. The finding of "no difference in mortality risks" relative to shift versus day work was consistent across all models examined. In the full model, performing manual work was no longer a significant explanatory factor in assessing mortality risk.

\section{Discussion}

Our findings pertain to shift work employees who have been given the opportunity to participate in a health protection program aimed at reducing the potential adverse health consequences of shift work.
Table 3. Category-specific prevalence risk ratios of rotating shift workers compared to day workers at entry to follow-up. (RR = relative risk, $95 \% \mathrm{Cl}=95 \%$ confidence interval)

\begin{tabular}{|c|c|c|}
\hline \multirow[t]{2}{*}{ Disease category a } & $\begin{array}{l}\text { Number with } \\
\text { outcome at entry }\end{array}$ & $\begin{array}{l}\text { Rotating shift } \\
\text { risk ratio }\end{array}$ \\
\hline & $\begin{array}{l}\text { Rotating Day } \\
\text { shift work }\end{array}$ & $95 \% \mathrm{Cl}$ \\
\hline
\end{tabular}

Employees with medical

examinations prior to entry

Cancer (C00-C43, C45-C99)

Diabetes mellitus (E10-E14)

Obesity (E65-E66)

Epilepsy (G40-G41)

Hypertensive diseases (I10-I14)

Ischemic heart disease (I20-I25)

Conductive heart disorders (144-149)

Cerebral vascular disease

(I60-169, G45)

Atherosclerosis (I70-178)

1339312028

$\begin{array}{llll}57 & 111 & 0.41 & 0.29-0.58\end{array}$

$\begin{array}{llll}356 \quad 223 & 1.16 & 0.96-1.41\end{array}$

$2665 \quad 1656 \quad 1.41 \quad 1.31-1.52$

$\begin{array}{llll}27 & 37 & 0.45 & 0.27-0.76\end{array}$

$\begin{array}{lllll}1276 & 1099 & 1.06 & 0.96-1.17\end{array}$

$\begin{array}{llll}145 & 145 & 0.74 & 0.57-0.96\end{array}$

$245 \quad 210 \quad 0.86 \quad 0.70-1.05$

Chronic obstructive pulmonary

disease (J43-J44)

Asthma (J45)

$44 \quad 47 \quad 0.65 \quad 0.41-1.02$

$\begin{array}{llll}57 & 45 & 0.73 & 0.48-1.13\end{array}$

Diseases of esophagus, stomach, duodenum (K20-K31)

Diseases of the liver (K70-K75, K77)

Diseases of gallbladder, biliary tract, pancreas (K80-K86)

$228 \quad 125 \quad 1.38 \quad 1.08-1.77$

$\begin{array}{llll}245 & 171 & 1.16 & 0.93-1.43\end{array}$

$\begin{array}{llll}540 \quad 321 & 1.10 & 0.95-1.28\end{array}$

$\begin{array}{llll}303 & 254 & 0.90 & 0.75-1.09\end{array}$

$\begin{array}{llll}123 & 85 & 1.08 & 0.79-1.47\end{array}$

a The code of International Classification of Diseases, 7th revision, is shown in parentheses.

b Based on logistic regression analysis controlling for age, job level, cigarette smoking, and alcohol intake.

During an 11-year observation period, employees in the shift work cohort took part in twice as many occupational medical examinations and health seminar days per work year, as day work employees. A key finding of our study was the marginally lower risk of premature death among shift compared to day work wage employees. This finding was robust with respect to adjustment for explanatory factors beyond age and job level, including cigarette smoking, alcohol intake, and prior health status relative to selected chronic disease conditions.

Both initial and ongoing selection into shift or day work may have had notable impacts on morbidity outcomes and subsequent mortality risks. From a historical perspective, employees with more severe health conditions were precluded or at least discouraged from entering shift work. Consideration of an employee's fitness for duty probably explains the deficits in the prevalence of cancer, epilepsy, and ischemic heart disease on date of entry to the study among shift work employees. It was unexpected that the reporting of new cancer, epilepsy, and cerebral vascular disease diagnoses after entry to the study continued to be lower among shift work employees. However, 
Table 4. Category-specific illness incidence rates per 1000 person years at risk among shift and day work employees (1996-2006). $(95 \% \mathrm{Cl}=95 \%$ confidence interval)

\begin{tabular}{|c|c|c|c|c|c|c|c|c|}
\hline \multirow[t]{2}{*}{ Disease category a } & \multicolumn{3}{|c|}{ Rotating shift } & \multicolumn{3}{|c|}{ Day work } & \multicolumn{2}{|c|}{ Shift employees } \\
\hline & $\mathrm{N}$ & $\begin{array}{l}\text { Person- } \\
\text { years }\end{array}$ & Rate $^{b}$ & $\mathrm{~N}$ & $\begin{array}{l}\text { Person- } \\
\text { years }\end{array}$ & Rate $^{b}$ & $\begin{array}{c}\text { Adjusted } \\
\text { hazard ratio }\end{array}$ & $95 \% \mathrm{Cl}$ \\
\hline Cancer (C00-C43, C45-C99) & 200 & 96884 & 2.06 & 175 & 65479 & 2.67 & 0.76 & $0.60-0.96$ \\
\hline Diabetes mellitus (E10-E14) & 671 & 94956 & 7.06 & 296 & 65021 & 4.55 & 1.33 & $1.14-1.55$ \\
\hline Obesity (E65-E66) & 1710 & 73975 & 23.11 & 721 & 49525 & 14.55 & 1.39 & $1.26-1.53$ \\
\hline Epilepsy (G40-G41) & 29 & 97396 & 0.29 & 22 & 66069 & 0.33 & 0.49 & $0.27-0.89$ \\
\hline Hypertensive diseases (I10-|14) & 1946 & 87068 & 22.35 & 1143 & 57447 & 19.89 & 1.09 & $1.00-1.18$ \\
\hline Ischemic heart disease (I20-I25) & 306 & 96650 & 3.16 & 187 & 65557 & 2.85 & 1.04 & $0.84-1.27$ \\
\hline Conductive heart disorders (144-149) & 440 & 95426 & 4.61 & 206 & 64980 & 3.17 & 1.25 & $1.04-1.51$ \\
\hline Cerebral vascular disease (I60-169, G45) & 123 & 97329 & 1.26 & 96 & 66023 & 1.45 & 0.71 & $0.53-0.96$ \\
\hline Atherosclerosis (170-178) & 91 & 97367 & 0.93 & 52 & 66055 & 0.78 & 0.94 & $0.64-1.38$ \\
\hline Chronic obstructive pulmonary disease (J43-J44) & 361 & 95694 & 3.77 & 129 & 65401 & 1.97 & 1.38 & $1.11-1.72$ \\
\hline Asthma (J45) & 281 & 95394 & 2.94 & 166 & 64939 & 2.55 & 0.91 & $0.74-1.13$ \\
\hline Diseases of esophagus, stomach, duodenum (K20-K31) & 425 & 93333 & 4.55 & 193 & 64046 & 3.01 & 1.22 & $1.01-1.48$ \\
\hline Diseases of the liver (K70-K75, K77) & 190 & 95358 & 1.99 & 119 & 64716 & 1.83 & 0.76 & $0.59-0.98$ \\
\hline Diseases of gallbladder, biliary tract, pancreas (K80-K86) & 158 & 96637 & 1.63 & 71 & 65673 & 1.08 & 1.37 & $1.00-1.87$ \\
\hline
\end{tabular}

a The code of International Classification of Diseases, 7th revision, is shown in parentheses.

${ }^{b}$ Crude incidence rate per 1000 person years at risk.

c Based on Cox proportional hazards model including age at entry, job level, cigarette smoking, alcohol intake, obesity, and interval between last examination prior to the start of the risk period and the risk period start date as covariates, as appropriate, and with stratification by mean interval between examinations after the start of the risk period

Table 5. Observed and expected deaths among rotating and day shift employees by age group and interval since entry. (SMR = standardized mortality ratio, $95 \% \mathrm{Cl}=95 \%$ confidence interval)

\begin{tabular}{|c|c|c|c|c|c|c|c|c|}
\hline \multirow[t]{2}{*}{ Job level } & \multicolumn{4}{|c|}{ Rotating shift employees } & \multicolumn{4}{|c|}{ Day shift employees } \\
\hline & $\begin{array}{c}\text { Observed } \\
\text { deaths }^{a}(\mathrm{~N})\end{array}$ & $\begin{array}{c}\text { Expected } \\
\text { deaths }^{\text {a }}(N)\end{array}$ & SMR & $95 \% \mathrm{Cl}$ & $\begin{array}{c}\text { Observed } \\
\text { deaths }^{a}(N)\end{array}$ & $\begin{array}{c}\text { Expected } \\
\text { deaths }^{a}(N)\end{array}$ & SMR & $95 \% \mathrm{Cl}$ \\
\hline \multicolumn{9}{|l|}{ Manual work (age group) } \\
\hline $\begin{array}{l}15-44 \text { years of age } \\
45-54 \text { years of age } \\
\geq 55 \text { years of age }\end{array}$ & $\begin{array}{r}54 \\
74 \\
212\end{array}$ & $\begin{array}{l}102.7 \\
127.5 \\
265.0\end{array}$ & $\begin{array}{l}0.53 \\
0.58 \\
0.80\end{array}$ & $\begin{array}{l}0.40-0.69 \\
0.46-0.73 \\
0.70-0.92\end{array}$ & $\begin{array}{r}45 \\
57 \\
112\end{array}$ & $\begin{array}{r}67.8 \\
75.5 \\
122.7\end{array}$ & $\begin{array}{l}0.66 \\
0.75 \\
0.91\end{array}$ & $\begin{array}{l}0.48-0.89 \\
0.57-0.98 \\
0.75-1.10\end{array}$ \\
\hline Total & 340 & 495.3 & 0.69 & $0.62-0.76$ & 214 & 266.0 & 0.80 & $0.70-0.92$ \\
\hline $\begin{array}{l}<10 \text { years since entry } \\
\geq 10 \text { years since entry }\end{array}$ & $\begin{array}{r}257 \\
82\end{array}$ & $\begin{array}{r}395.6 \\
99.7\end{array}$ & $\begin{array}{l}0.65 \\
0.82\end{array}$ & $\begin{array}{l}0.57-0.73 \\
0.65-1.02\end{array}$ & $\begin{array}{r}181 \\
33\end{array}$ & $\begin{array}{r}225.0 \\
41.0\end{array}$ & $\begin{array}{l}0.80 \\
0.80\end{array}$ & $\begin{array}{l}0.69-0.92 \\
0.55-1.13\end{array}$ \\
\hline \multicolumn{9}{|c|}{ Skilled and supervisory (age group) } \\
\hline $\begin{array}{l}15-44 \text { years of age } \\
45-54 \text { years of age } \\
\geq 55 \text { years of age }\end{array}$ & $\begin{array}{l}10 \\
15 \\
49\end{array}$ & $\begin{array}{l}15.6 \\
29.0 \\
69.5\end{array}$ & $\begin{array}{l}0.64 \\
0.52 \\
0.71\end{array}$ & $\begin{array}{l}0.31-1.18 \\
0.29-0.85 \\
0.52-0.93\end{array}$ & $\begin{array}{r}33 \\
56 \\
160\end{array}$ & $\begin{array}{r}69.3 \\
114.7 \\
267.9\end{array}$ & $\begin{array}{l}0.48 \\
0.49 \\
0.60\end{array}$ & $\begin{array}{l}0.33-0.67 \\
0.37-0.63 \\
0.51-0.70\end{array}$ \\
\hline Total & 74 & 114.1 & 0.65 & $0.51-0.81$ & 249 & 451.9 & 0.55 & $0.48-0.62$ \\
\hline $\begin{array}{l}<10 \text { years since entry } \\
\geq 10 \text { years since entry }\end{array}$ & $\begin{array}{l}57 \\
17\end{array}$ & $\begin{array}{l}90.8 \\
23.2\end{array}$ & $\begin{array}{l}0.63 \\
0.73\end{array}$ & $\begin{array}{l}0.48-0.81 \\
0.43-1.17\end{array}$ & $\begin{array}{r}186 \\
63\end{array}$ & $\begin{array}{r}367.9 \\
84.0\end{array}$ & $\begin{array}{l}0.51 \\
0.75\end{array}$ & $\begin{array}{l}0.44-0.58 \\
0.58-0.96\end{array}$ \\
\hline
\end{tabular}

a Based on 5-year age- and calendar period-specific mortality rates for total German male population, 1995-2006.

it is possible that there may have been late reporting of earlier diagnoses in these categories among day workers given their less frequent examinations.

Several conditions, namely obesity and COPD, were more prevalent among shift work employees on entry to the follow-up. Both cross-sectional (23-24) and longitudinal $(8,10)$ studies have reported increases in body mass index (BMI) among shift compared to day work employees. However, in a very large study (25), the difference in the percent of shift compared to day employees with BMI $\geq 30 \mathrm{~kg} / \mathrm{m}^{2}$ was greater in 30 year-olds than older men, suggesting that the BMI differences might predate the decision to enter shift work. Our finding regarding pre-study entry obesity could be 
Table 6. Relative risk (RR) of death in shift workers compared to day work employees in models including different co-factors. $(95 \% \mathrm{Cl}$ $=95 \%$ confidence interval)

\begin{tabular}{|c|c|c|c|c|c|c|c|}
\hline & & & \multicolumn{2}{|c|}{ Shift work } & \multicolumn{3}{|c|}{ Co-factors in model } \\
\hline & & & $\mathrm{RR}$ & $95 \% \mathrm{Cl}$ & Variable & $\mathrm{RR}$ & $\begin{array}{l}\text { P-value } \\
\text { (2-sided) }\end{array}$ \\
\hline 1 & 877 & 31346 & 0.95 & $0.82-1.10$ & $\begin{array}{l}\text { Age at entry } \\
\text { Manual work }\end{array}$ & $\begin{array}{l}1.11 \\
1.35\end{array}$ & $\begin{array}{c}<0.0001 \\
0.0001\end{array}$ \\
\hline 2 & 787 & $29261^{a}$ & 0.88 & $0.75-1.03$ & $\begin{array}{l}\text { Age at entry } \\
\text { Manual work } \\
\text { Cigarette smoking }\end{array}$ & $\begin{array}{l}1.11 \\
1.24 \\
1.73\end{array}$ & $\begin{array}{c}<0.0001 \\
0.0112 \\
<0.0001\end{array}$ \\
\hline 3 & 748 & $27967^{\mathrm{a}}$ & 0.88 & $0.75-1.03$ & $\begin{array}{l}\text { Age at entry } \\
\text { Manual work } \\
\text { Cigarette smoking } \\
\text { Alcohol intake }\end{array}$ & $\begin{array}{l}1.11 \\
1.25 \\
1.70 \\
1.13\end{array}$ & $\begin{array}{l}<0.0001 \\
0.0099 \\
<0.0001 \\
0.0002\end{array}$ \\
\hline 4 & 689 & $24545^{a}$ & 0.91 & $0.77-1.07$ & $\begin{array}{l}\text { Age at entry } \\
\text { Manual work } \\
\text { Cigarette smoking } \\
\text { Alcohol intake } \\
\text { Cancer less non-melanoma skin } \\
\text { Epilepsy } \\
\text { Cerebral vascular disease } \\
\text { Diseases of the liver } \\
\text { Diabetes mellitus } \\
\text { Ischemic heart disease } \\
\text { Chronic obstructive pulmonary disease } \\
\text { Conductive heart disorders } \\
\text { Hypertensive diseases }\end{array}$ & $\begin{array}{l}1.09 \\
1.13 \\
1.64 \\
1.10 \\
4.68 \\
2.98 \\
2.60 \\
2.54 \\
2.19 \\
1.85 \\
1.66 \\
1.64 \\
1.32\end{array}$ & $\begin{array}{c}<0.0001 \\
0.1771 \\
<0.0001 \\
0.0054 \\
<0.0001 \\
0.0042 \\
<0.0001 \\
<0.0001 \\
<0.0001 \\
0.0003 \\
0.0068 \\
0.0043 \\
0.0041\end{array}$ \\
\hline
\end{tabular}

a Decreased numbers due to missing smoking or alcohol intake data, or lack of a medical examination prior to entry date.

related to predisposing factors not assessed in the study or to prior exposure to shift work. The latter possibility could not be tested due to the lack of reliable data on shift status before 1995. However, we also observed an increase in obesity diagnoses during the incidence phase of the study. We will further investigate this finding using quantitative analysis of weight gains as there are plausible arguments supporting a connection between shift work and weight gain (9).

The increased occurrences of COPD among shift work employees at the start of the follow-up and in subsequent incidence rates could be partly due to a lack of specificity in our analyses regarding the number of cigarettes smoked per day. In a 1996 Helicobacter pylori intervention study (15) that included over 4600 participants from the present study, we found that shift work employees smoked more heavily than their corresponding day employees. Thus, cigarette smoking could be both more prevalent (and involve a greater daily intake of cigarettes) among shift compared to day work employees, but prevalence data were available only for our current analyses. It is possible that shift work leads to increased smoking; however, it has been reported that future shift workers were more likely to have smoked cigarettes prior to entering shift work than future day workers (26). Additionally, stratification by examination frequency in the incidence rate analyses adjusts for differences in examination rates, but only indirectly for differences in diagnostic measures during the individual medical examinations. Given a more intense medical surveillance program for shift work employees (both in terms of frequency and comprehensiveness of the examinations), it is again possible that differential knowledge of disease status could arise relative to diagnosis of chronic COPD. Thus, it is most likely that factors other than shift work per se account for the differences in COPD incidence rates between shift and day work employees.

A relative increase in the incidence of diabetes mellitus was also observed among shift compared to day work employees, even after adjustment for the presence of obesity on entry to the follow-up. Diabetes has been linked to shift work in several prior studies $(4-5,27)$. The relative risks reported in these studies were close to our own findings. Further efforts may be needed to develop appropriate dietary guidance for employees in shift work as weight gain has been associated with shift work and, in a crosssectional study, total nutrient intake was increased in employees performing night shifts (9).

For hypertensive diseases and conductive heart disorders, there were also marginally increased risk ratios for shift compared to day work employees. Again, there is some external evidence supporting an increased risk of hypertensive disease $(2,28)$ 
and conductive heart disorders via an increase in the frequency of premature ventricular complexes found in a one-year follow-up study of 49 shift and 22 day workers (29). In our data, premature ventricular depolarization represented only 29 and $28 \%$ of the diagnoses in the conductive heart disease category for shift and day work employees, respectively. Thus, within this category, there was no propensity for this diagnosis to be differentially distributed among shift compared to day work employees.

Two subcategories of digestive system disorders were also at least marginally elevated among shift work employees. The most frequent diagnoses in the K20-K31 category were gastritis and duodenitis (32\%), gastro-esophageal reflux disease $(31 \%)$ and gastric or duodenal ulcer $(26 \%)$. The distribution of specific diagnoses within the overall category, however, did not differ among shift compared to day work employees. Similarly, there was no differential distribution of specific diagnoses by type of shift within the K80-K86 category; the most frequent diagnoses being cholelithiasis $(62 \%)$ and other diseases of the pancreas (26\%). A higher prevalence of gastric and duodenal ulcers has been reported among shift compared to day work employees in several studies (30-31). In our Helicobacter pylori initiative, shift work was not associated with a higher ulcer or non-ulcer dyspepsia prevalence, although it was associated with positive Helicobacter pylori serology (15). Taking part in the Helicobacter pylori initiative was a significant predictor of subsequent K20-K31 diagnoses, but inclusion of this factor in our incidence analysis for the present study did not diminish the elevated risk ratio for shift work in the category.

The increased detection of obesity, diabetes, and diseases of the circulatory and digestive system in this study among rotating shift compared to day work employees is in general agreement with findings from prior studies $(2,4-5,8-10,27-28,30-31)$. Counterintuitively, however, this did not result in increased premature mortality in our shift work employees. This "lack of effect" may well be due to a combination of factors related both to the health protection program and the nature of the rotating shift systems employed at this work site. The enhanced medical surveillance may have resulted in earlier detection and treatment of health problems known to be linked to shift work, resulting in a better long-term outcome. Additionally, the fast forward-rotating 12-hour shift system with shift changes at 06.00 and 18.00 hours may be important. For example, we have previously shown a reduction in commuting accidents and deaths associated with this system compared with the experience of day work employees (18). It may also be that the type of shift system in use at this work site is less prone to cause internal desynchronization between different circadian rhythms, compared to slow or even backwards rotating shift patterns. Such "chronodisruption" has been suggested as the underlying cause for various adverse health effects associated with shift work (3234). Because the shift system analyzed in this study is not representative of all industries, our results may not be easily extrapolated to other populations of shift workers and cannot serve to dismiss concerns about the health hazards of shift work in general. Furthermore, this long-standing health surveillance program targeting shift work employees may not be typical of the programs provided in other work settings.

A major aim of the BASF Medical Department has been to provide comprehensive and cost-effective approaches to improving overall employee health while addressing specific occupational health and safety issues such as those related to shift work. This strategy combines preventive health examinations, health promotion activities, and the provision of 24hour on-site emergency medical services. As resources permit, the Medical Department also undertakes other disease prevention programs such as the Helicobacter pylori initiative mentioned earlier (15), and weight reduction and diabetes prevention programs (16-17).

There are indications of an important synergy among the various programs. We have found, for example, that participants in the health seminar programs were also more likely to participate in the Helicobacter pylori initiative. Health seminar attendees, who participated prior to the start of the study risk period, were also more likely to participate again in the program at a later date. Furthermore, prior participation in the seminar program is itself associated with both increased detection of chronic disease conditions and substantially decreased mortality risks independent of shift work status (data not shown).

Taken as a whole, a program combining occupational medical examinations, health seminars, and other intervention programs can be beneficial in mitigating the long-term health consequences of (i) shift work and (ii) an anticipated aging of the workforce, the latter being linked to shifts in general population demographics and societal adjustment of policies regarding retirement age.

\section{Acknowledgements}

This research was initiated within the Occupational Medical and Health Protection Department and conducted during the normal course of employment within the company; otherwise, no conflict of interest is declared. 


\section{References}

1. Knutsson A. Health disorders of shift workers. Occup Med. 2003;53:103-8.

2. Morikawa Y, Nakagawa H, Miura K, Ishizaki M, Tabata $\mathrm{M}$, Nishijo $\mathrm{M}$, et al. Relationship between shift work and onset of hypertension in a cohort of manual workers. Scand J Work Environ Health. 1999;25(2):100-4.

3. Virtanen SV, Notkola V. Socioeconomic inequalities in cardiovascular mortality and the role of work: a register study of Finnish men. Int J Epidemiol. 2002;31:614-21.

4. Morikawa Y, Nakagawa H, Miura K, Soyama Y, Ishizaki M, Kido T, et al. Shift work and the risk of diabetes mellitus among Japanese male factory workers. Scand J Work Environ Health. 2005;31(3):179-83.

5. Karlsson B, Alfredsson L, Knutsson A, Andersson E, Torén K. Total mortality and cause-specific mortality of Swedish shiftand dayworkers in the pulp and paper industry in 1952-2001. Scand J Work Environ Health. 2005;31(1):30-5.

6. Fujino Y, Iso H, Tamakoshi A, Inaba Y, Koizumi A, Kubo $\mathrm{T}$, et al. A prospective cohort study of shift work and risk of ischemic heart disease in Japanese male workers. Am J Epidemiol. 2006;164:128-35.

7. Tüchsen F, Hannerz H, Burr H. A 12 year prospective study of circulatory disease among Danish shift workers. Occup Environ Med. 2006;63:451-5.

8. Morikawa Y, Nakagawa H, Miura K, Soyama Y, Ishizaki M, Kido T, et al. Effect of shift work on body mass index and metabolic parameters. Scand J Work Environ Health. 2007;33(1):45-50.

9. Morikawa Y, Miura K, Sasaki S, Yoshita K, Yoneyama S, Sakurai M, et al. Evaluation of the effects of shift work on nutrient intake: a cross-sectional study. J Occup Health. 2008;50:270-8.

10. Suwazono Y, Dochi M, Sakata K, Okubo Y, Oishi M, Tanaka $\mathrm{K}$, et al. A longitudinal study on the effect of shift work on weight gain in male Japanese workers. Obesity (Silver Spring). 2008;16:1887-93.

11. Boggild H, Suadicani P, Hein HO, Gyntelberg F. Shift work, social class, and ischaemic heart disease in middle aged and elderly men; a 22 year follow up in the Copenhagen male study. Occup Environ Med. 1999;56:640-5.

12. Yadegarfar G, McNamee R. Shift work, confounding and death from ischaemic heart disease. Occup Environ Med. 2008;65:158-63.

13. Knutsson A. Shift work and ischaemic heart disease. Occup Environ Med. 2008;65:152.

14. Schiebeler H, Pluto R, Germann C, et al. Preventive occupational medical examinations of shift workers. In: Costa G, Cesana G, Kogi K, Wedderburn A, editors. Shiftwork: Health, Sleep and Performance; Proceedings of the IX International Symposium on Night and Shift Work, Verona, Italy, 1989. Frankfurt am Main (Germany): Peter Lang, 1990. p 608-16.

15. Zober A, Schilling D, Ott MG, Schauwecker P, Riemann
JF, Messerer P. Helicobacter pylori infection: prevalence and clinical relevance in a large company. J Occup Environ Med. 1998;40:586-94.

16. Oberlinner C, Lang S, Germann C, Trauth B, Eberle F, Pluto R, et al. [Prevention of overweight and obesity in the workplace: BASF-health promotion campaign "trim down the pounds - losing weight without losing your mind"]. Gesundheitswesen. 2007;69:385-92.

17. Oberlinner C, Neumann SM, Ott MG, Zober A. Screening for pre-diabetes in the workplace. Occup Med. 2008;58:41-5.

18. Ott MG, Oberlinner C, Lang S, Hoffmann G, Nasterlack M, Pluto R-P, et al. Health and safety protection for chemical industry employees in a rotating shift system: program design and acute injury and illness experience at work. J Occup Environ Med. 2009;51:221-31.

19. Bambra CL, Whitehead MM, Sowden AJ, Akers J, Petticrew MP. Shifting schedules - the health effects of reorganizing shift work. Am J Prev Med. 2008;34:427-34.

20. Zober A. Occupational health services in Germany and the use of routine data for epidemiology and management: example from the chemical industry. J Ambul Care Manage. 1994;17:11-8.

21. Zober A, Pluto R. Primärprävention - Ein Aufgabenfeld für die Arbeitsmedizin [Primary prevention - a task for occupational medicine]. Arbeitsmed Sozialmed Präventivmed. 1991;15:55-60.

22. Statistisches Bundesamt. [Causes of death in Germany]. Wiesbaden (Germany): Statistisches Bundesamt; 2007. Fachserie 12, Reihe 4.

23. Parkes KR. Shift work and age as interactive predictors of body mass index among offshore workers. Scand J Work Environ Health. 2002;28(1):64-71.

24. Di Lorenzo L, De Pergola G, Zocchetti C, L'Abbate N, Basso A, Pannacciulli N, et al. Effect of shift work on body mass index: results of a study performed in 319 glucosetolerant men working in a Southern Italian industry. Int J Obesity. 2003;27:1353-8.

25. Karlsson B, Knutsson A, Lindahl B. Is there an association between shift work and having a metabolic syndrome?: results from a population based study of 27,485 people. Occup Environ Med. 2001;58:747-52.

26. Nabe-Nielsen K, Garde AH, Tüchsen F, Hogh A, Diderichsen F. Cardiovascular risk factors and primary selection into shift work. Scand J Work Environ Health. 2008;34(3):206-12.

27. Suwazono Y, Sakata K, Okubo Y, Harada H, Oishi M, Kobayashi E, et al. Long-term longitudinal study on the relationship between alternating shift work and the onset of diabetes mellitus in male Japanese workers. J Occup Environ Med. 2006;48:455-61.

28. Suwazono Y, Dochi M, Sakata K, Okubo Y, Oishi M, Tanaka $\mathrm{K}$, et al. Shift work is a risk factor for increased blood pressure in Japanese men - a 14-year historical cohort study. Hypertension. 2008;52:581-6.

29. van Amelsvoort LG, Schouten EG, Maan AC, Swenne CA, 
Kok FJ. Changes in frequency of premature complexes and heart rate variability related to shift work. Occup Environ Med. 2001;58:678-81.

30. Segawa K, Nakazawa S, Tsukamoto Y, Kurita Y, Goto H, Fukui A, et al. Peptic ulcer is prevalent among shift workers. Dig Dis Sci. 1987;32:449-53.

31. Pietroiusti A, Forlini A, Magrini A, Galante A, Coppeta L, Gemma G, et al. Shift work increases the frequency of duodenal ulcer in H. pylori infected workers. Occup Environ Med. 2006;63:773-5.

32. Garaulet M, Madrid JA. Chronobiology, genetics and metabolic syndrome. Curr Opin Lipidol. 2009;20:127-34.
33. Straif K, Baan R, Grosse Y, Secretan B, El Ghissassi F, Bouvard V, et al. Carcinogenicity of shift-work, painting, and fire-fighting. Lancet Oncol. 2007;8:1065-6.

34. Erren TC, Morfeld P, Stork J, Knauth P, von Mülmann MJA, Breitstadt R, et al. Shift work, chronodisruption and cancer? - the IARC 2007 challenge for research and prevention and 10 theses from the Cologne Colloquium 2008 [discussion paper]. Scand J Work Environ Health. 2009;35(1):74-9.

Received for publication: 29 January 2009 